\title{
Homocysteine levels in patients of type 2 diabetes mellitus with diabetic nephropathy and its clinical implications
}

\author{
Singla $\mathbf{H}^{1}$, Panag $\mathrm{KMDS}^{2}$, Batta $\mathrm{A}^{3}$, Goyal $\mathbf{G}^{4}$ \\ ${ }^{1}$ Dr. Heena Singla, MD Biochemistry, Senior Resident, ${ }^{2}$ Dr. KMDS Panag, MD Biochemistry, Professor and Head, ${ }^{3}$ Dr \\ Anil Batta, MD Biochemistry, Professor, ${ }^{4}$ Dr Gitanjali Goyal, MD Biochemistry, Associate Professor. All are affiliated \\ with Department of Biochemistry, Baba Farid University of Health Sciences, Faridkot, Punjab, India
}

Address for Correspondence: Dr. Heena Singla, drheenasingla@gmail.com

\begin{abstract}
Introduction: Diabetic nephropathy is one of the most common and serious complications of long standing type 2 diabetes mellitus. Microalbuminuria is a strong predictor of diabetic nephropathy. Homocysteine level plays an important role in pathogenesis of diabetic microvascular complications, particularly diabetic nephropathy. Vitamin $\mathrm{B}_{12}$, Folic acid and Vitamin $\mathrm{B}_{6}$ facilitate homocysteine metabolism. Methods: This case- control study was carried out at a tertiary care centre. Total 150 subjects were enrolled, which included 60 cases of type 2 diabetes with microalbuminuria, 60 cases of type 2 diabetes without microalbuminuria and 30 healthy controls. Besides routine investigations, fasting blood glucose, glycated haemoglobin, and homocysteine levels in serum were measured. All subjects were screened for microalbuminuria. Statistical analysis was done. Results: Homocysteine levels, fasting blood glucose and glycated haemoglobin were significantly higher in patients of type 2 diabetes with microalbuminuria as compared to those without microalbuminuria $(\mathrm{p}=0.00, \mathrm{p}=0.01, \mathrm{p}=0.01)$. Strong positive correlation was observed between the homocysteine levels and degree of microalbuminuria $(\mathrm{r}=+0.758, \mathrm{p}=0.00)$, and also between the fasting blood glucose levels and degree of microalbuminuria $(r=+0.259, \mathrm{p}=0.02)$. Conclusions: It would be useful to perform an early screening for raised homocysteine levels and for low vitamin levels in the patients of uncontrolled diabetics. This would help to evaluate the need of folic acid, Vitamin $\mathrm{B}_{12}$ and Vitamin $\mathrm{B}_{6}$ supplements since these supplements can be beneficial for delaying the progress of diabetic nephropathy in these patients.
\end{abstract}

Keywords: Homocysteine, Diabetic Nephropathy, Microalbuminuria, Type 2 Diabetes Mellitus.

\section{Introduction}

Diabetes mellitus in all its heterogeneity has taken a central stage as one of the ultimate medical challenges all over the world. According to a WHO Reporting group, the total number of people with diabetes is projected to rise from to 366 million by 2030 [1]. Diabetic nephropathy is one of the major long term complications of diabetes mellitus[2]. It is the leading cause of diabetes mellitus related morbidity and mortality.

1.1 Microalbuminuria and its relation to diabetic nephropathy: Microalbuminuria is the hallmark of diabetic nephropathy in its earliest stages [3].

Manuscript received: $20^{\text {th }}$ Sept 2015

Reviewed: $4^{\text {th }}$ Oct 2015

Author Corrected: $16^{\text {th }}$ Octt 2015

Accepted for Publication: 29 $9^{\text {th }}$ Octt 2015
According to a study, diabetic nephropathy can be detected at quite an early stage by detection of microalbuminuria. It is defined as urinary albumin excretion rate(AER) in the range of $30-300 \mathrm{mg} / \mathrm{day}$ [4]. Normal value of urinary albumin excretion is less than $20 \mathrm{mg} / \mathrm{L}$ [5]. Microalbuminuria is a risk factor for development of overt renal failure [6]. It is an independent risk factor for development of cardiovascular disease in patients with diabetes mellitus, hypertension, and even in the general population.[7].

1.2 Homocysteine metabolism: Homocysteine is a sulphur containing amino acid. It is not present in food, but is generated from methionine via transmethylation reactions [8]. Homocysteine is either converted to cysteine via a series of vitamin $\mathrm{B}_{6}$ dependent processes, 
or it is remethylated to methionine. The first pathway of homocysteine metabolism is catalysed by enzyme cystathione $\beta$ - synthase which needs vitamin $B_{6}$. The second pathway requires enzyme homocysteine methyl transferase, methyl tetrahydrofolate and Vitamin $B_{12}$. [9] Hence mentainence of normal blood level of these three vitamins i.e. Folic acid, Vitamin $B_{12}$ and Vitamin $B_{6}$ is very important to keep homocysteine levels in control.

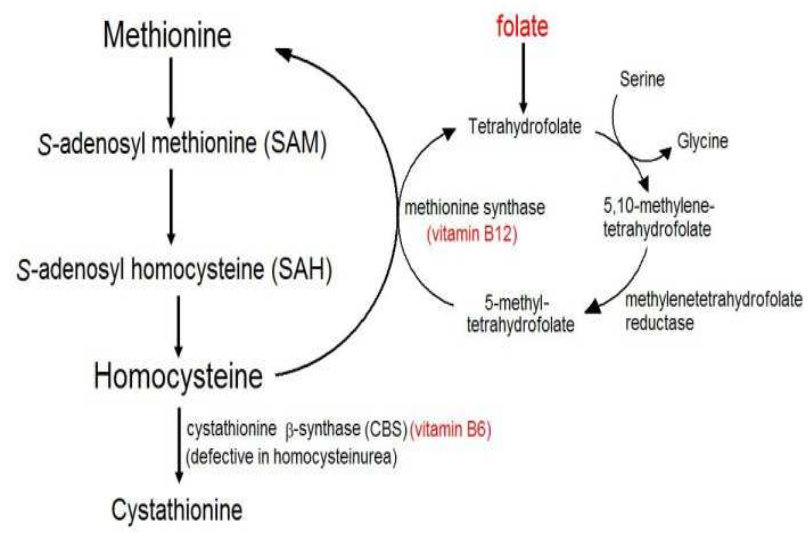

Metabolic pathways showing the relationship between homocysteine, methionine, Vitamin $\mathbf{B}_{6}$, Vitamin $B_{12}$ and Folic acid

1.3 Diabetes mellitus and homocysteine levelsRelationship to diabetic nephropathy: Increased serum homocysteine level is a risk factor for accelerated atherosclerosis [10]. Patients with homocysteinuria display early onset of arteriosclerosis and venous thrombosis [11,12]. High levels of homocysteine are believed to promote the formation of oxidation products such as homocysteine disulfide and homocysteine thiolactone. These oxidation products damage vascular endothelium by causing excessive sulfation of collagen, which in turn promotes thrombosis and arteriosclerosis. Diabetes mellitus is a clearly recognised risk factor for accelerated atherosclerosis, which is two to three times more common than in normal non-diabetic population [13]. The association between increased homocysteine levels and atherosclerotic vascular disease has been shown to be especially strong in type 2 diabetes [14]. It is one of the major causes for development of diabetic microvascular and macrovascular complications, especially diabetic nephropathy.

Homocysteine levels are closely linked with creatinine clearance since it is also partially excreted by kidneys. Its levels have been found to be elevated in patients with impaired renal function, particularly in patients with end stage renal disease $[15,16]$. Hyperhomocysteinemia correlates with both change in glomerular filteration rate (GFR)[17], as well as the presence of microalbuminuria $[18,19]$. Cross-sectional studies have proved that rise in homocysteine level precedes the development of microalbuminuria, and its level correlates with the degree of microalbuminuria and worsening of other diabetic microvascular complications [20]. So the present study was intended to compare serum homocysteine levels in patients of type 2 diabetes mellitus with and without diabetic nephropathy and to find correlation of its level with severity of the disease.

\section{Materials and Methods}

2.1 Study design: This hospital-based case control study was carried out at a tertiary care centre during June 2011 to May 2014. The study was conducted after obtaining clearance from the thesis and ethical committee of the institution. Participants' voluntary consent (oral and written) was obtained after explanation of the purpose, method and course of the study. A total number of 150 subjects were enrolled in the study. These 150 study subjects were grouped as follows:

1. Group A comprised 60 cases of type 2 diabetes with microalbuminuria.

2. Group B comprised 60 cases of type 2 diabetes without microalbuminuria .

3. Group C comprised of 30 healthy controls.

Exclusion criteria was not to consider those patients with liver disease, thyroid disorders, females on oral contraceptives, pregnant and lactating mothers because of the associated hormonal changes which affect body metabolism. Patients on anti-epileptic and anti-cancer drugs were also excluded from the study since these patients show false high levels of homocysteine.

A detailed questionnaire was completed for all patients regarding age, gender, smoking history, history of alcohol consumption, family history, duration of diabetes, history of hypertension and history of any medication. Screening for diabetic nephropathy was done by detection of microalbuminuria using Nycocard Reader i.e. if more than $20 \mathrm{mg} / \mathrm{L}$ [5].

Around three millilitres of venous blood sample was collected from the patient on the day of examination. Relevant routine investigations were performed which included haemogram, complete urine analysis, fasting blood glucose, blood urea, serum creatinine, uric acid, bilirubin, AST, ALT, Alkaline phosphatase, electrolytes, calcium and complete lipid profile. All 
these investigations were performed on Beckman Coulter AU 480 fully automated analyser. An early morning first-voided spot urine sample was collected for detection of microalbuminuria. Serum homocysteine level was measured on Siemens Immulite 1000 Chemiluminescence, based on the principle of competitive immunoassay [21]. The normal value of homocysteine is 5-12 $\mu \mathrm{mol} / \mathrm{L}$ [22]. Glycated haemoglobin and microalbuminuria were measured on Nycocard Reader, based on the principle of solid phase, sandwich format, immunometric assay [23,24].

Glomerular filteration rate (GFR) was estimated based on the value of serum creatinine by using CockcroftGault formula.[25].
eGFR $=[(140$-age $) \times$ weight $\times 0.85$ if female $] /(72 \times \mathrm{S} \mathrm{Cr})$, adjusted for BSA by $1.73 \mathrm{~m}^{2} / \mathrm{BSA}$

2.2 Statistical analysis: Statistical Package for Social Sciences (SPSS) version 16 was used to perform statistical analysis. Baseline characteristics of the study subjects were presented as mean \pm standard deviation. ANOVA (Analysis of variance ) and Post-Hoc tests were used for multiple comparisons between the groups, and to calculate the level of significance of difference in parameters between different groups( $p$ value). $\mathrm{p}$ value $<0.05$ was considered as statistically significant. Pearson's correlation coefficient ( $r$ value) was calculated between the suggested biomarkers i.e. homocysteine, microalbuminuria, fasting blood glucose and glycated haemoglobin.

\section{Results}

For the present case-control study, subjects were taken after age and sex matching. We compared all the important biochemical parameters between the three groups which included serum homocysteine levels, fasting blood glucose and glycated haemoglobin.

As shown in Table 1, all the parameters showed highest levels in patients of type 2 diabetes with microalbuminuria (Group A) in comparison with diabetics without microalbuminuria (Group B) and healthy controls (Group C). Patients of Group A revealed serum homocysteine level in the range of $12.9-25.7 \mu \mathrm{mol} / \mathrm{L}$. In patients of Group B, serum homocysteine level was in the range of $7.1-14.4 \mu \mathrm{mol} / \mathrm{L}$. In patients of Group C comprising healthy controls, serum homocysteine level was in the range of $6.2-9.5 \mu \mathrm{mol} / \mathrm{L}$ (normal value of homocysteine is $5-12 \mu \mathrm{mol} / \mathrm{L}$ ). In comparison with Group B and C subjects, Group A patients had much higher serum homocysteine levels ( $\mathrm{p}=0.00$ ), fasting blood glucose levels $(\mathrm{p}=0.01)$, and glycated haemoglobin $(\mathrm{p}=0.01)$. Values of these parameters in healthy controls $(\mathrm{Group} C)$ were in normal range. These $\mathrm{p}$ values established significant difference in the levels of all these parameters among the three groups.

Table 1: Comparison of different relevant parameters amongst the three study groups*

\begin{tabular}{|l|l|l|l|l|}
\hline Variables & $\begin{array}{l}\text { Group A } \\
\text { (Diabetics with } \\
\text { microalbuminuria) } \\
\mathbf{n = 6 0}\end{array}$ & $\begin{array}{l}\text { Group B } \\
\text { (Diabetics without } \\
\text { microalbuminuria) } \\
\mathbf{n = 6 0}\end{array}$ & $\begin{array}{l}\text { Group C } \\
\text { (Healthy controls) } \\
\text { n=30 }\end{array}$ & p value $\dagger$ \\
\hline $\begin{array}{l}\text { FBS (mg\%) } \\
(\mathbf{m m o l} / \mathbf{L})\end{array}$ & $\begin{array}{l}182.9 \pm 62.4 \\
(10.1 \pm 3.4)\end{array}$ & $\begin{array}{l}128.8 \pm 40.9 \\
(7.1 \pm 2.2)\end{array}$ & $\begin{array}{l}99.4 \pm 8.8 \\
(3.5 \pm 0.5)\end{array}$ & $0.01(\mathrm{HS})$ \\
\hline $\begin{array}{l}\text { HbA1c } \mathbf{\%}) \\
(\mathbf{m m o l} / \mathbf{L})\end{array}$ & $\begin{array}{l}7.51 \pm 2.1 \% \\
(\text { mean of } 58 \mathrm{mmol} / \mathrm{L})\end{array}$ & $\begin{array}{l}5.7 \pm 0.8 \% \\
(\text { mean of } 45 \mathrm{mmol} / \mathrm{L})\end{array}$ & $\begin{array}{l}5.4 \pm 0.2 \% \\
(\mathrm{mean} \text { of } 36 \mathrm{mmol} / \mathrm{L})\end{array}$ & $0.01(\mathrm{HS})$ \\
\hline $\mathbf{H c y}(\boldsymbol{\mu m o l} / \mathbf{L})$ & $19.3 \pm 6.5$ & $10.8 \pm 3.7$ & $7.9 \pm 1.7$ & $0.00(\mathrm{HS})$ \\
\hline eGFR $(\mathbf{m l} / \mathbf{m i n})$ & $108.1 \pm 5.3$ & $120.2 \pm 7.4$ & $129.4 \pm 6.2$ & $0.00(\mathrm{HS})$ \\
\hline
\end{tabular}

FBS: Fasting blood glucose, HbA1c: Glycosylated haemoglobin, Hcy: Homocysteine, eGFR: effective Glomerular filteration rate, HS: Highly significant, SD: Standard deviation

$*$ Values expressed as mean \pm 1 S.D; $\nmid$ p value $<0.01$ : Highly significant

Pearson's correlation coefficient was calculated between the concerned parameters. As depicted in Table 2, patients of type 2 diabetes with microalbuminuria(Group A) showed significant positive correlation between the serum 
homocysteine levels and the degree of microalbuminuria( $\left.\mathrm{r}=+0.758^{* *}, \mathrm{p}=0.00\right)$ which indicates high level of significance. With increasing degree of microalbuminuria, there was corresponding increase in homocysteine levels in these patients.(Table 2, Figure 1)

Table 2: Pearson's correlation coefficient between relevant parameters in Group A patients

\begin{tabular}{|l|l|l|}
\hline Parameters & Correlation coefficient(r value)* & p value $^{*}$ \\
\hline$\mu$ Alb \& Hcy & +0.758 & 0.00 \\
\hline FBS \& HbA1c & +0.586 & 0.01 \\
\hline FBS \& $\mu$ Alb & +0.259 & 0.02 \\
\hline
\end{tabular}

$\mu$ Alb: Microalbuminuria, FBS: Fasting blood glucose, HbA1c: Glycosylated haemoglobin, Hcy: Homocysteine *Positive $r$ value indicates positive correlation;

$\dagger \mathrm{p}$ value $<0.01$ : Highly significant

Figure 1: Scatter plot showing correlation between homocysteine levels and degree of microalbuminuria in Group A type 2 diabetes subjects with diabetic nephropathy.

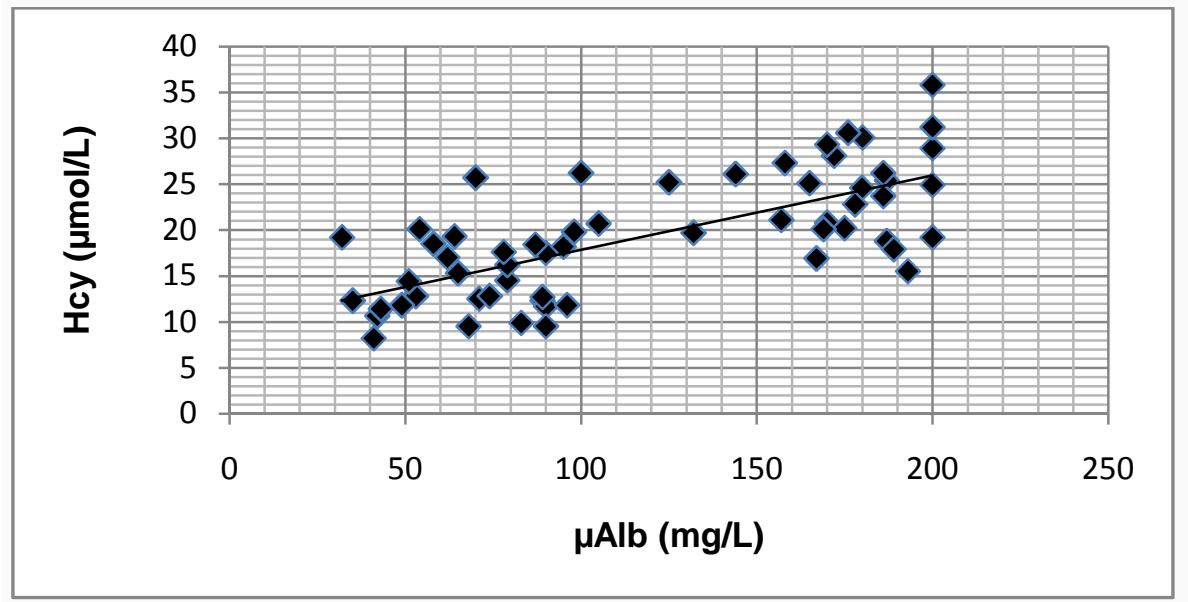

Hcy: Homocysteine, $\mu$ Alb: Microalbuminuria

Our study results showed strong positive correlation between fasting blood glucose levels and the degree of microalbuminuria $\left(\mathrm{r}=+0.259^{* *}, \mathrm{p}=0.02\right)$ indicating high level of significance. So uncontrolled diabetics had higher degree of diabetic nephropathy.

Both groups of type 2 diabetes(Group A and Group B) revealed strong positive correlation between fasting blood glucose and glycated haemoglobin $\left(\mathrm{r}=+0.586^{* *}, \mathrm{p}=0.01\right)$ indicating high level of significance. Hence glycated haemoglobin is a very good and reliable indicator of blood glucose over a particular period in diabetic patients.

\section{Discussion}

Diabetic nephropathy is one of the major causes of diabetes mellitus related morbidity and mortality. In the present case-control study, we compared seum homocysteine levels in cases of type 2 diabetes with microalbuminuria, diabetes without microalbuminuria and healthy controls. All the three groups were age and sex- matched.

Our study results illustrated strong positive correlation between fasting blood glucose levels and the degree of microalbuminuria $\left(\mathrm{r}=+0.259^{* *}, \mathrm{p}=0.02\right)$. Poor glycemic control has been a well known risk factor for progression of diabetic nephropathy. Keeping a tight glycemic control prevents the kidney damage in uncontrolled diabetes [26]. This fact is supported by a study which showed that uncontrolled diabetics with nephropathy had strong positive association between glycated haemoglobin and degree of microalbuminuria [27].

In our present study, homocysteine levels were found to be highest in patients of type 2 diabetes with 
microalbuminuria in comparison to the patients of type 2 diabetes without microalbuminuria and healthy controls $(\mathrm{p}=0.00)$. The healthy controls had normal homocysteine levels(i.e. 5-12 $\mu$ mol/l) [22]. Diabetic patients with microalbuminuria showed strong positive correlation between the homocysteine levels and degree of microalbuminuria $\left(\mathrm{r}=+0.758^{* *}, \mathrm{p}=0.00\right)$. Most of these patients with microalbuminuria more than 180 $\mathrm{mg} / \mathrm{L}$ had homocysteine levels above $20 \mu \mathrm{mol} / \mathrm{l}$. Hence with increasing degree of microalbuminuria, the levels of homocysteine were also more.

According to the Hoorn study by Jager A et al, increased level of homocysteine is an independent determinant of the development of (micro)albuminuria, and the cumulative incidence of (micro)albuminuria increases with categories of increasing homocysteine levels [28]. The Hoorn Hoorn study proved strong association between increased homocysteine level and the degree of microalbuminuria. A similar crosssectional study proved that increased serum homocysteine levels are correlated with (micro)albuminuria and contribute to worsening microvascular damage in type 2 diabetes [20]. Another similar study established that proteinuria is a predictor of total serum homocysteine levels in patients of type 2 diabetes with diabetic nephropathy [29]. These different studies support our results.

The exact pathogenesis of diabetic nephropathy is multifactorial and remains largely unclear. Intact renal endothelial and mesangial cell function is important for regulation of intraglomerular pressure and glomerular capillary membrane size selectivity. Dysfunction of these cells may increase intraglomerular pressure and/or decrease glomerular capillary membrane size selectivity. In patients of uncontrolled type 2 diabetes, increased serum homocysteine level is associated with vascular endothelial cell dysfunction, chronic inflammation and oxidative stress [30]. Increased levels of homocysteine cause increased generation of free radicals which cause endothelial and mesangial cells dysfunction in glomerular capillaries. This leads to development and progression of microalbuminuria in these patients.

Hyperhomocysteinemia is a well established risk factor for the development of macrovascular disease including coronary artery disease[31,32]. Since it is partially removed from body by renal clearance, its levels are particularly elevated in patients with diabetic nephropathy, and particularly in those with end stage renal disease.

By facilitating the normal metabolism of homocysteine, blood levels of folate, vitamin $\mathrm{B}_{12}$ and vitamin $\mathrm{B}_{6}$ are among the important predictors of homocysteine levels $[33,34]$. Many cross-sectional studies have shown that circulating levels of homocysteine are increased in individuals with dietary deficiency of folate and/or cyanocobalamin [29,35]. In some studies, folic acid and vitamin $B_{12}$ supplements have been proved to be helpful to decrease homocysteine levels in circulation [35,36].

\section{Key Message and Conclusion}

This study proved that high serum homocysteine level is an important independent risk factor for development of diabetic nephropathy in type 2 diabetes patients (as detected by presence of microalbuminuria). In view of the proven relationship between hyperhomocysteinemia and vascular injury, its levels must be kept under control in patients with uncontrolled diabetes. Our study could be of clinical use because increased levels of homocysteine can be effectively controlled by administration of folic acid, Vitamin $\mathrm{B}_{12}$ and Vitamin $\mathrm{B}_{6}$ supplements. So these medications can be beneficial in delaying the progress of diabetic nephropathy in the patients of uncontrolled diabetes who have proven deficiency of these vitamins.

Acknowledgements: Authors are thankful to statistician Dr. Ghansham Sharma for his help in statistical analysis of the data. The authors are thankful to all the volunteers who participated in the study.

Roles of authors: The corresponding author Dr. Heena Singla carried out the complete study and wrote the manuscript. Dr. KMDS Panag contributed to revision of the manuscript. Dr. Anil Batta and Dr. Gitanjali Goyal contributed to discussion.

Disclosure statement: All authors approve that this final article is true. All authors have materially participated in the research and article preparation.

Conflict of interest: None declared. Funding: Nil, Permission from IRB: Yes

\section{References}

1. King H, Rewers M. Global estimates for prevalence of diabetes mellitus and impaired glucose tolerance in 
adults. WHO Ad Hoc Diabetes Reporting Group. Diabetes Care. 1993 Jan;16(1):157-77.

\section{Zargar AH, Wani AI, Masoodi SR, Laway} BA, Bashir MI. Mortality in diabetes mellitus--data from a developing region of the world. Diabetes Res Clin Pract. 1999 Jan;43(1):67-74.

3. Mogensen CE, Christensen CK, Vittinghus E. The stages in diabetic renal disease. With emphasis on the stage of incipient diabetic nephropathy. Diabetes. 1983 May;32 Suppl 2:64-78.

4. Lehmann R, Spinas GA. [Diabetic nephropathy: significance of microalbuminuria and proteinuria in Type I and Type II diabetes mellitus]. Praxis (Bern 1994). 1995 Oct 31;84(44):1265-71.

5. Deckert T, Feldt-Rasmussen B, Borch-Johnsen $\mathrm{K}$, Jensen T, Kofoed-Enevoldsen A. Albuminuria reflects widespread vascular damage. The Steno hypothesis. Diabetologia. 1989 Apr;32(4):219-26.

6. Dinneen SF, Gerstein HC. The association of microalbuminuria and mortality in non-insulindependent diabetes mellitus. A systematic overview of the literature. Arch Intern Med. 1997 Jul $14 ; 157(13): 1413-8$.

7. Gerstein HC, Mann JF, Yi Q, Zinman B, Dinneen SF, Hoogwerf B, Hallé JP, Young J, Rashkow A, Joyce C, Nawaz S, Yusuf S; HOPE Study Investigators. Albuminuria and risk of cardiovascular events, death, and heart failure in diabetic and nondiabetic individuals. JAMA. 2001 Jul 25;286(4):421-6.

8. Mudd SH, Uhlendorf BW, Freeman JM, Finkelstein JD, Shih VE. Homocysteinuria associated with decreased methylene tetrahydrofolate reductase activity. Biochem Biophys Res Commun 1972 Jan; 46(2): 905912, PMID: 5057914

9. Mudd SH, Poole JR. Labile methyl balances for normal humans on various dietary regimens. Metabolism. 1975 Jun;24(6):721-35.

10. McCully KS. Vascular pathology of homocysteinemia: implications for the pathogenesis of arteriosclerosis. Am J Pathol. 1969 Jul;56(1):111-28.

11. Cattaneo M. Hyperhomocysteinemia and thrombosis. Lipids 2001 Jan;36(1): pp. S13- S26.
12. Heijer M, Keijzer MB. Hyperhomocysteinemia as a risk factor for venous thrombosis. Clin Chem Lab Med. 2001 Aug;39(8):710-3.

13. Kannel WB, McGee DL. Diabetes and cardiovascular disease. The Framingham study. JAMA. 1979 May 11;241(19):2035-8.

14. Hoogeveen EK, Kostense PJ, Becks PJ, Mackay AJ, Jakobs C, Bouter LM, et al. Hyperhomocysteinemia is associated with an increased risk of cardiovascular disease, especially in non-insulin dependent diabetes mellitus: A population-based study. Arteriosclerosis Thrombosis and Vascular Biology 1998; 18: 133-38, doi: 10.1161/01.ATV.18.1.133

15. Davies L, Wilmshurst EG, McElduff A, Gunton J, Clifton-Bligh P, Fulcher GR. The relationship among homocysteine, creatinine clearance, and albuminuria in patients with type 2 diabetes. Diabetes Care. 2001 Oct;24(10):1805-9.

16. Hultberg B, Agardh E, Andersson A, Brattström $\mathrm{L}$, Isaksson $\mathrm{A}$, Israelsson $\mathrm{B}$, Agardh $\mathrm{CD}$. Increased levels of plasma homocysteine are associated with nephropathy, but not severe retinopathy in type 1 diabetes mellitus. Scand J Clin Lab Invest. 1991 May;51(3):277-82.

17. Wollesen F, Brattström L, Refsum H, Ueland PM, Berglund L, Berne C. Plasma total homocysteine and cysteine in relation to glomerular filtration rate in diabetes mellitus. Kidney Int. 1999 Mar;55(3):1028-35.

18. Fonseca VA, Reynolds T, Fink LM. Hyperhomocysteinemia and microalbuminuria in diabetes. Diabetes Care. 1998 Jun;21(6):1028.

19. Chico A, Pérez A, Córdoba A, Arcelús R, Carreras G, de Leiva A, González-Sastre F, Blanco-Vaca F. Plasma homocysteine is related to albumin excretion rat e in patients with diabetes mellitus: a new link betweendiabetic nephropathy and cardiovascular disease? Diabetologia. 1998 Jun;41(6):684-93.

20. Lanfredini M, Fiorina P, Peca MG, Veronelli A, Mello A, Astorri E, Dall'Aglio P, Craveri A. Fasting and post-methionine load homocyst(e)ine values are correlated with microalbuminuria and could contribute to worsening vascular damage in non-insulin-dependent diabetes mellitus patients. Metabolism. 1998 Aug;47(8):915-21. 
21. Ueland PM, Refsum H, Stabler SP, Malinow MR, Andersson A, Allen RH. Total homocysteine in plasma or serum: methods and clinical applications. Clin Chem. 1993 Sep;39(9):1764-79.

22. Nehler MR, Taylor LM Jr, Porter JM Homocysteinemia as a risk factor for atherosclerosis: a review. Cardiovasc Pathol. 1997 Jan;6(1):1-9. doi: 10.1016/S1054-8807(96)00064-6.

23. Gomes MB, Lucchetti MR, Gonclaves MFR, Gazzolla H, Dimetz T, Matos H. Influence of first morning urine volume, fasting blood glucose and glycosylated haemoglobin on first morning urinary albumin concentration. Braz J Med Biol Res.1997 Feb; 30(2): 191-96, PMID: 9239304.

24. Jeppsson JO, Kobold U, Barr J, Finke A, Hoelzel W, Hoshino T, Miedema K, Mosca A, Mauri P, Paroni R, Thienpont L, Umemoto M, Weykamp $\mathrm{C}$; International Federation of Clinical Chemistry and Laboratory Medicine (IFCC). Approved IFCC reference method for the measurement of $\mathrm{HbA} 1 \mathrm{c}$ in human blood. Clin Chem Lab Med. 2002 Jan;40(1):7889.

25. Cockcroft DW, Gault MH. Prediction of creatinine clearance from serum creatinine. Nephron. 1976;16(1):31-41.

26. Sheikh SA, Baig JA, Iqbal T, Kazmi T, Baig M, Husain SS. Prevalence of microalbuminuria with relation to glycemic control in type-2 diabetic patients in Karachi. J Ayub Med Coll Abbottabad. 2009 JulSep;21(3):83-6.

27. Brownlee M, Hirsch IB. Glycemic variability: a hemoglobin A1c-independent risk factor for diabetic complications. JAMA. 2006 Apr 12;295(14):1707-8.

28. Jager A, Kostense PJ, Nijpels G, Dekker JM, Heine RJ, Bouter LM, Donker AJ, Stehouwer CD. Serum homocysteine levels are associated with the development of (micro)albuminuria: the Hoorn study. Arterioscler Thromb Vasc Biol. 2001 Jan;21(1):74-81.

29. Friedman AN, Hunsicker LG, Selhub J, Bostom AG; Collaborative Study Group. Proteinuria as a predictor of total plasma homocysteine levels in type

2 diabetic nephropathy. Diabetes

Care. 2002 Nov;25(11):2037-41.

30. Hofmann MA, Kohl B, Zumbach MS, Borcea V, Bierhaus A, Henkels M, Amiral J, Fiehn W, Ziegler R, Wahl P, Nawroth PP. Hyperhomocyst(e)inemia and endothelial dysfunction in IDDM. Diabetes Care. 1997 Dec;20(12):1880-6.

31. Fanapour PC, Yug B, Kochar MS. Hyperhomocysteinemia: an additional cardiovascular risk factor. WMJ. 1999 Dec;98(8):51-4.

32. Lippi G, Arosio E, Prior M, Guidi G. Biochemical risk factors for cardiovascular disease in an aged male population: emerging vascular pathogens. Angiology. 2001 Oct;52(10):681-7.

33. Lussier-Cacan S, Xhignesse M, Piolot A, Selhub J, Davignon J, Genest J Jr. Plasma total homocysteine in healthy subjects: sexspecific relation with biological traits. Am J Clin Nutr. 1996 Oct;64(4):587-93.

34. Selhub J, Jacques PF, Wilson PW, Rush D, Rosenberg IH. Vitamin status and intake as primary determinants of homocysteinemia in an elderly population. JAMA. 1993 Dec 8;270(22):2693-8.

35. Mudd SH. Diseases of sulphur metabolism: implications for the methionine-homocysteine cycle, and vitamin responsiveness. Ciba Found Symp. 1979;(72):239-58.

36. Mudd SH. Diseases of sulphur metabolism: implications for the methionine-homocysteine cycle, and vitamin responsiveness. Ciba Found Symp. 1979;(72):239-58.

\section{How to cite this article?}

Singla H, Panag KMDS, Batta A, Goyal G. Homocysteine levels in patients of type 2 diabetes mellitus with diabetic nephropathy and its clinical implications. Int J Med Res Rev 2015;3(9):1070-1076. doi: 10.17511/ijmrr.2015.i9.195. 